\title{
Educação em saúde e educação na saúde: conceitos e implicações para a saúde coletiva
}

\author{
Health education and education in the health system: \\ concepts and implications for public health
}

Mirian Benites Falkenberg ${ }^{1}$

Thais de Paula Lima Mendes ${ }^{1}$

Eliane Pedrozo de Moraes ${ }^{1}$

Elza Maria de Souza ${ }^{1}$

\footnotetext{
${ }^{1}$ Programa de PósGraduação em Saúde Coletiva, Universidade de Brasília (UnB). Campus Universitário Darcy Ribeiro s/n, Asa Norte. 70.910-900 Brasília DF Brasil. mirianfalk@hotmail.com
}

\begin{abstract}
The scope of this paper is to analyze the key concepts and expressions related to health education and education in the health system and their interfaces in the field of Public Health. Since there are various interpretations among health professionals regarding such terminologies and their variants in daily practice, it is necessary to establish the difference between them. Consequently, an attempt is also made to establish the difference between the variants of the first, such as sanitary education, education for health and popular health education, which represent a series of practices that involve social participation to increase the autonomy of individuals and the community in order to make choices and to pursue a healthy lifestyle. The variants of the second include ongoing education and in-service education, namely the education provided to health professionals to improve their knowledge in the field of health, in order to improve the health care afforded to the population.
\end{abstract}

Key words Health education, Ongoing education
Resumo O presente artigo tem como objetivo analisar os conceitos-chave relativos à Educação em Saúde e Educação na Saúde e suas interfaces no campo da Saúde Coletiva. Embora apresentem diferenças, é frequente na prática dos serviços, a utilização das diversas variantes a elas relacionadas de forma indistinta. Dessa forma busca-se, também, distinguir dentro desses conceitos-chave as variantes da primeira, tais como, educação sanitária, educação e saúde, educação para a saúde e educação popular em saúde que significa um conjunto de práticas de educação para indivíduos e comunidade a fim de aumentar a autonomia das pessoas e da comunidade para que possam fazer escolhas e adotar hábitos saudáveis de vida e as variantes da segunda, tais como educação permanente em saúde e educação continuada ministrada para profissionais de saúde a fim de aprimorar o conhecimento destes e a atenção dispensada à população.

Palavras-chave Educação em saúde, Educação continuada 


\section{Introdução}

Os trabalhadores da área da saúde coletiva sabem que o uso de neologismos é comum e, inevitavelmente, passam a usar os novos termos que surgem, atribuindo a eles significados diferentes, ou não. Neologismo significa "palavra ou expressão nova, ou antiga com sentido novo"1. As expressões saúde pública e saúde coletiva, atenção básica e atenção primária, educação em saúde e educação popular em saúde, educação continuada e educação permanente são exemplos que ilustram essa ideia.

O presente artigo tem como objetivo discutir os conceitos de educação em saúde e educação na saúde e suas interfaces, visto serem áreas de conhecimento e práticas relacionadas ao campo da saúde. Na prática dos serviços o uso dos termos educação e saúde, educação para a saúde, educação popular em saúde, educação sanitária, educação permanente e educação continuada têm sido utilizados de forma indistinta pelos profissionais.

A fim de reduzir equívocos e facilitar o entendimento de tais termos entre profissionais e estudantes da área da saúde sugere-se adotar os termos utilizados pelo Ministério da Saúde (MS) em sua Biblioteca Virtual em Saúde (BVS)².

\section{Educação em saúde}

O MS define educação em saúde como:

Processo educativo de construção de conhecimentos em saúde que visa à apropriação temática pela população [...]. Conjunto de práticas do setor que contribui para aumentar a autonomia das pessoas no seu cuidado e no debate com os profissionais e os gestores a fim de alcançar uma atenção de saúde de acordo com suas necessidades ${ }^{2}$.

As práticas de educação em saúde envolvem três segmentos de atores prioritários: os profissionais de saúde que valorizem a prevenção e a promoção tanto quanto as práticas curativas; os gestores que apoiem esses profissionais; e a população que necessita construir seus conhecimentos e aumentar sua autonomia nos cuidados, individual e coletivamente. Embora a definição do MS apresente elementos que pressupõem essa interação entre os três segmentos das estratégias utilizadas para o desenvolvimento desse processo, ainda existe grande distância entre retórica e prática.

A educação em saúde como processo político pedagógico requer o desenvolvimento de um pensar crítico e reflexivo, permitindo desvelar a realidade e propor ações transformadoras que levem o indivíduo à sua autonomia e emancipação como sujeito histórico e social, capaz de propor e opinar nas decisões de saúde para cuidar de si, de sua família e de sua coletividade ${ }^{3}$.

A temática deve envolver a compreensão de projetos de sociedades e visões de mundo que se atualizam nas formas de conceber e organizar os discursos e as práticas educativas no campo da saúde ${ }^{4}$.

As práticas de educação em saúde são inerentes ao trabalho em saúde, mas muitas vezes estão relegadas a um segundo plano no planejamento e organização dos serviços, na execução das ações de cuidado e na própria gestão.

O termo educação em saúde vem sendo utilizado desde as primeiras décadas do século XX e para sua melhor compreensão faz-se necessário o entendimento da história da saúde pública no Brasil. A expansão da medicina preventiva para algumas regiões do país, a partir da década de 1940, com o Serviço Especial de Saúde Pública (SESP), apresentava estratégias de educação em saúde autoritárias, tecnicistas e biologicistas, em que as classes populares eram vistas e tratadas como passivas e incapazes de iniciativas própri$a^{5}$. As ações do Estado se davam por meio das chamadas campanhas sanitárias.

Outras formas de educação em saúde eram caracterizadas por ações verticais de caráter informativo com o intuito de transformar hábitos de vida, colocando o indivíduo como o responsável pela sua saúde. Um trabalho realizado por Alves e Aerts em $2011^{6}$ afirma:

[...] com o apogeu do paradigma cartesiano e da medicina científica, as responsabilidades referentes às ações de educação em saúde foram divididas entre os trabalhadores da saúde e os da educação. Aos primeiros, cabia desenvolver os conhecimentos científicos capazes de intervir sobre a doença, diagnosticando-a e tratando-a o mais rapidamente possível. Ao educador, cabia desenvolver ações educativas capazes de transformar comportamentos. Essa lógica, além de fragmentar o conhecimento, não levava em consideração os problemas cotidianos vivenciados pela população.

O termo educação e saúde, utilizado ainda hoje como sinônimo de educação em saúde, pode ter se originado dessa prática, indicando um paralelismo entre as duas áreas, com separação explícita dos seus instrumentos de trabalho: a educação ocupando-se dos métodos pedagógicos para transformar comportamentos e a saúde dos conhecimentos científicos capazes de intervir sobre as doenças.

Exemplo clássico de como se davam as práticas educativas em saúde na época ficou registra- 
do na obra do escritor infanto-juvenil Monteiro Lobato, que criou em seu livro Urupês, obra publicada em 1918, o personagem Jeca Tatu, trabalhador rural do Vale do Paraíba (SP), um caboclo que sofria do amarelão, doença posteriormente diagnosticada como ancilostomose ou ancilostomíase, denunciando as precárias condições de vida da população. À época, as campanhas sanitárias utilizaram a figura do personagem indicando que as origens dos problemas de saúde eram de responsabilidade individual, não contextualizando os problemas sanitários de forma crítica a partir de mudanças coletivas.

Na década de 1990 ainda era comum o uso do termo educação e saúde, e o conceito apresentava-se como uma área de saber técnico voltada para instrumentalizar o controle dos doentes pelos serviços e a prevenção de doenças pelas pessoas ${ }^{7}$.

O desenvolvimento da educação sanitária, iniciada nos Estados Unidos, deu-se de forma associada à saúde pública, tendo sido instrumento das ações de prevenção das doenças, caracterizando-se pela transmissão de conhecimento. Mesmo que realizada de forma massiva, como no caso das campanhas sanitárias no Brasil, a perspectiva não contemplava a dimensão histórico-social do processo saúde-doença ${ }^{4}$. No Brasil o termo foi e ainda é utilizado, como sinônimo de educação em saúde, mantendo a conotação de práticas educativas verticalizadas.

Educação para a saúde também é outro termo usual ainda hoje nos serviços de saúde. Aqui se supõe uma concepção mais verticalizada dos métodos e práticas educativas, que remete ao que Paulo Freire $^{8}$ chamou de educação bancária. Nesse sentido, é como se os profissionais de saúde devessem ensinar uma população ignorante o que precisaria ser feito para a mudança de hábitos de vida, a fim de melhorar a saúde individual e coletiva.

Muitas práticas educativas nos serviços de saúde ainda são feitas com esta visão, apesar da participação comunitária estar presente na retórica de muitos gestores, profissionais de saúde e educadores e preconizada nos princípios e diretrizes do SUS?.

Movimentos sociais, tais como o Movimento de Educação Popular, protagonizado pelo educador Paulo Freire, na década de 1960, influenciaram o campo de práticas da educação em saúde, incorporando a participação e o saber popular à área, dando lugar a processos educativos mais democráticos. Exemplo dessa influência foi verificado no Movimento de Educação Popular em Saúde que se formou nos últimos 40 anos, por meio de reflexão, produção de conhecimentos e militância em diversas organizações criadas ao longo deste tempo, tais como a Articulação Nacional de Educação Popular em Saúde, a Rede de Educação Popular e Saúde, a Articulação Nacional de Movimentos e Práticas de Educação Popular e Saúde e a Rede de Estudos sobre Espiritualidade no Trabalho em Saúde e na Educação Popular ${ }^{10}$.

A educação popular em saúde é um movimento histórico de mudanças, inicialmente propostas por profissionais de saúde insatisfeitos com as práticas mercantilizadas e repetitivas dos serviços de saúde, que não atendiam às camadas mais necessitadas da população brasileira. Vasconcelos $^{5}$ considera que a educação popular em saúde passou a se constituir em uma estratégia de enfrentamento aos problemas de saúde encontrados, procurando fortalecer os movimentos sociais e criar vínculos entre a ação médica e o pensar cotidiano da população.

A educação popular em saúde tem uma concepção diferenciada da hegemônica da educação em saúde. Organiza a partir da aproximação com outros sujeitos no espaço comunitário, privilegiando os movimentos sociais locais, num entendimento de saúde como prática social e global e tendo como balizador ético-político os interesses das classes populares. Baseia-se no diálogo com os saberes prévios dos usuários dos serviços de saúde, seus saberes “populares", e na análise crítica da realidade.

A educação em saúde, então, é prática privilegiada no campo das ciências da saúde, em especial da saúde coletiva, uma vez que pode ser considerada no âmbito de práticas onde se realizam ações em diferentes organizações e instituições por diversos agentes dentro e fora do espaço convencionalmente reconhecido como setor saúde $e^{11}$.

A educação popular em saúde continua sendo hoje um desafio aos gestores e profissionais na busca por práticas integrais, mais voltadas às reais necessidades das populações e considerando, como suporte para essas práticas, tanto processos de informação e comunicação como de participação popular e participação social.

Para promover a educação em saúde, também é necessário que ocorra a educação voltada para os profissionais de saúde, e se fala, então, em educação na saúde.

\section{Educação na saúde}

Educação na saúde, de acordo com o glossário eletrônico da $\mathrm{BVS}^{12}$, consiste na produção e 
sistematização de conhecimentos relativos à formação e ao desenvolvimento para a atuação em saúde, envolvendo práticas de ensino, diretrizes didáticas e orientação curricular.

Os cenários de atuação dos profissionais da saúde são os mais diversos e com o rápido e constante desenvolvimento de novas tecnologias. Além de exigências diárias envolvendo inteligência emocional e relações interpessoais se faz necessário que haja algo para além da graduação, que possa tornar os profissionais sempre aptos a atuarem de maneira a garantir a integralidade do cuidado, a segurança deles próprios como trabalhadores e dos usuários e a resolubilidade do sistema.

Nesse processo de múltiplas determinações e relações torna-se fundamental o papel das instituições de serviço para o desenvolvimento das capacidades dos profissionais, de maneira a contribuir para essa formação.

Nesse contexto o traço original da educação deste século é a colocação do indivíduo nos contextos social, político e ético-ideológico. A educação no século XX tornou-se permanente e social e as ideias universalmente difundidas entre elas é a de que não há idade para se educar, de que a educação estende-se pela vida e ela não é neutra, mas engajada ${ }^{13}$.

Para tanto, há duas modalidades de educação no trabalho em saúde: a educação continuada e a educação permanente.

A educação continuada envolve as atividades de ensino após a graduação, possui duração definida e utiliza metodologia tradicional, tais como as pós-graduações, enquanto a educação permanente estrutura-se a partir de dois elementos: as necessidades do processo de trabalho e o processo crítico como inclusivo ao trabalho ${ }^{14}$.

Para o Glossário eletrônico da BVS ${ }^{12}$, educação continuada, consiste no processo de aquisição sequencial e acumulativa de informações técnico-científicas pelo trabalhador, por meio de escolarização formal, de vivências, de experiências laborais e de participação no âmbito institucional ou fora dele.

O primeiro grande marco da educação continuada aconteceu na década de 1950, com a reunião de Elsinor, ocorrida na Dinamarca em 1959, patrocinada pela Unesco, em que se discutiram os fins e os métodos da educação de adultos e o papel da cooperação internacional, na reconstrução do pós-guerra. $\mathrm{O}$ enfoque desse encontro era a compreensão de que todo conhecimento sofre transformações, sendo necessário aprender a capacitar-se. O lema vigente na época era "Há de ajustar-se a um mundo novo em mutação"15.
O segundo momento histórico manifesta-se na década de 1960 e tem como princípio aceitar o adulto como passível de aprender, mas de maneira diferente da criança e do adolescente. $\mathrm{O}$ enfoque é técnico institucional, devido a isso, aparecem projetos multinacionais de incentivo à capacitação de mão-de-obra ${ }^{16}$.

Na década de 1970, o terceiro marco histórico, caracteriza-se pelo pensamento de que o homem "educa-se a partir da realidade que o cerca e, em interação com outros homens, coeducase". É uma fase que coloca o homem consciente, dentro da realidade onde vive, interagindo como sujeito transformador ${ }^{16}$.

Complementando o pensamento acima, "o aprendizado adulto é pessoal, é ter a vida como educação, pois é um processo que dura a vida toda, que todos nós temos em comum e que alimenta o ciclo da mudança de comportamento, é, portanto, um processo de evolução"17. A educação continuada caracteriza-se por alternativas educacionais mais centradas no desenvolvimento de grupos profissionais, seja por meio de cursos de caráter seriado, seja por meio de publicações específicas em determinado campo ${ }^{18}$.

Já a educação permanente consiste em ações educativas embasadas na problematização do processo de trabalho em saúde e que tenham como objetivo a transformação das práticas profissionais e da própria organização do trabalho, tomando como referência as necessidades de saúde das pessoas e das populações, a reorganização da gestão setorial e a ampliação dos laços da formação com o exercício do controle social em saúde ${ }^{12}$.

O desafio da educação permanente é estimular o desenvolvimento da consciência nos profissionais sobre o seu contexto, pela sua responsabilidade em seu processo permanente de capacitação. Assim, é necessário que os serviços de saúde revejam os métodos utilizados em educação permanente, de forma que esta seja um processo participativo para todos. Ela tem como cenário o próprio espaço de trabalho, no qual o pensar e o fazer são insumos fundamentais do aprender e do trabalhar ${ }^{19}$. Essa seria uma educação muito mais voltada para a transformação social do que para a transmissão cultural ${ }^{13}$.

Para a construção do SUS é fundamental a reorientação do modelo assistencial vigente e hegemônico no país. Este modelo, que resulta de uma combinação complementar e, ao mesmo tempo, antagônica do modelo médico privatista e do modelo assistencial "sanitarista" dicotomiza a assistência e a prevençãa ${ }^{20}$. Acrescentaríamos que ele ainda ignora a promoção da saúde, a qual 
extrapola o sistema de saúde para uma abordagem mais ampla que envolve a integração intersetorial e o entendimento abrangente da saúde como um fenômeno também social que "empodera" indivíduos e comunidade.

Faz-se essencial compreender o que traduz um modelo assistencial e, sobretudo, o que implica sua reorientação. $\mathrm{O}$ modelo de atenção ou modelo assistencial "[...] é uma dada forma de combinar técnicas e tecnologias para resolver problemas e atender necessidades de saúde individuais e coletivas. É uma razão de ser, uma racionalidade, uma espécie de lógica que orienta a ação"20.

É possível perceber, voltando o olhar para o cenário atual, que há necessidade de complementação do atual modelo de atenção assistencialista, centrado na doença, excessivamente especializado e ainda prioritariamente hospitalar, por um modelo integral, que priorize a promoção da saúde e a prevenção de agravos, e que utilize a educação em saúde de forma participativa e dialógica. Contudo, alterações no processo de formação profissional e reflexão sobre suas práticas podem auxiliar nessa mudança de paradigma.

É importante, então, a utilização de metodologias de ensino-aprendizagem participativas e dialógicas, tais como as utilizadas nas ações de educação popular em saúde, inseridas nos currículos de educação continuada e nas ações de educação permanente em saúde, visando uma formação profissional em saúde mais adequada às necessidades de saúde individuais e coletivas, na perspectiva da equidade e da integralidade.

\section{Considerações finais}

Considera-se importante distinguir e caracterizar os conceitos-chave de educação em saúde e educação na saúde, visto que são práticas fundamentais nesse campo. Apesar de suas distinções apresentam conexões que devem ser alvo de reflexão por parte dos atuais e futuros profissionais de saúde.

Na educação em saúde deve ser enfatizada a educação popular em saúde, que valoriza os saberes, o conhecimento prévio da população e não somente o conhecimento científico. Na educação na saúde deve ser enfatizada a educação permanente em saúde, de maneira a buscar nas lacunas de conhecimento dos profissionais, ações direcionadas a qualificação dos processos de trabalho em saúde considerando as especificidades locais e as necessidades do trabalho real.

\section{Colaboradores}

MB Falkenberg, TPL Mendes, EP Moraes e EM Souza participaram igualmente de todas as etapas de elaboração do artigo. 


\section{Referências}

1. Ferreira ABH. Mini Aurélio: o dicionário da língua portuguesa. Curitiba: Positivo; 2010.

2. Brasil. Ministério da Saúde (MS). Secretaria de Gestão do Trabalho e da Educação na Saúde. Departamento de Gestão e da Regulação do Trabalho em Saúde. Câmara de Regulação do Trabalho em Saúde. Brasília: MS; 2006.

3. Machado MFAS, Monteiro EMLM, Queiroz DT, Vieira NFC, Barroso MGT. Integralidade, formação de saúde, educação em saúde e as propostas do SUS - uma revisão conceitual. Cien Saude Colet 2007; 12(2):335-342.

4. Morosini MV, Fonseca AF, Pereira I. Educação em Saúde. In: Pereira IB, Lima JCF, organizadores. Dicionário de Educação Profissional em Saúde. Rio de Janeiro: EPSJV; 2008. p. 155-162.

5. Vasconcelos EM. Participação popular e educação nos primórdios da saúde pública brasileira. In: Vasconcelos EM, organizador. A saúde nas palavras e nos gestos: reflexões da Rede de Educação Popular nos Serviços de Saúde. São Paulo: Editora Hucitec; 2001.

6. Alves GG, Aerts D. As práticas educativas em saúde e a Estratégia Saúde da Família. Cien Saude Colet 2011; 6(1):319-325.

7. Stotz EM. Enfoques sobre educação e saúde. In: Valla VV, Stotz EM, organizadores. Participação popular, educação e saúde: teoria e prática. Rio de Janeiro: Relume-Dumará; 1993. p. 11-22.

8. Freire P. Pedagogia do oprimido. 17ª Edição. São Paulo: Paz e Terra; 1987.

9. Brasil. Presidência da República. Lei 8.080 , de 19 de setembro de 1990. Dispõe sobre as condições para a promoção, proteção e recuperação da saúde, a organização e o funcionamento dos serviços correspondentes e dá outras providências. Diário Oficial da União 1990; 20 set.

10. Gomes LB, Merhy EE. Compreenderndo a educação popular em saúde: um estudo na literatura brasileira. Cad Saude Publica 2011; 27(1):7-18.

11. Paim J, Almeida Filho N. Saúde Coletiva: uma "nova saúde pública" ou campo aberto a novos paradigmas? Rev Saude Publica 1998; 32(4):299-316.
12. Brasil. Ministério da Saúde (MS). Secretaria-Executiva. Secretaria de Gestão do Trabalho e da Educação na Saúde. Glossário temático: gestão do trabalho e da educação na saúde. Brasília: Editora do Ministério da Saúde; 2009. (Série A. Normas e Manuais Técnicos).

13. Gadotti M. Perspectivas atuais da Educação. São Paulo em Perspectiva 2000; 2(14):3-11.

14. Motta JIJ, Ribeiro ECO, Worzoler MCC, Barreto CMG, Candal S. Educação permanente em saúde. Olho Mágico 2002; 9(1):67-78.

15. Barroso MGT, Varela ZMV. Educação continuada: requisito básico para o crescimento profissional. In: Anais do XXXI Congresso Brasileiro de Enfermagem, Fortaleza, 1979. Fortaleza, Associação Brasileira de Enfermagem - seção Ceará, p. 101-106. 1979.

16. Luz S. Educação continuada: estudo descritivo de instituições hospitalares. O mundo da saúde 2000; 24(5):343-351.

17. Koerich MS. Enfermagem e patologia geral: resgate e reconstrução de conhecimentos para uma prática interdisciplinar [dissertação]. Florianópolis: Universidade Federal de Santa Catarina; 2002.

18. Backes VMS, Schmidt SMS, Nietsche EA. Educação continuada: algumas considerações na história da educação e os reflexos na enfermagem. Texto Contexto enfermagem 2003; 12(1):80-88.

19. Ricaldoni CAC, Sena RR. Educação permanente: uma ferramenta para pensar e agir no trabalho de enfermagem. Rev. Latino-Am. Enfermagem 2006; 14(6):837-842.

20. Paim JS. Modelos de atenção e vigilância da saúde. In: Rouquayrol MZ, Almeida-Filho N, organizadores. Epidemiologia e saúde. 6a Edição. Rio de Janeiro: Medsi; 2003. p. 567-586.

Artigo apresentado em 08/01/2013

Aprovado em 15/03/2013

Versão final apresentada em 20/03/2013 